\title{
EFICÁCIA DE GESTÃO DO PARQUE NACIONAL DOS CAMPOS GERAIS, PARANÁ ${ }^{1}$
}

\section{MANAGEMENT EFFECTIVENESS OF THE NATIONAL PARK OF THE CAMPOS GERAIS, PARANÁ}

\author{
Saimon Francisco Dos Santos Bach¹, Isonel Sandino Meneguzzo ${ }^{1 *}$, Juliane Coimbra \\ Bczuska $^{2}$, Giulliano Hilgenberg de Oliveira Capote ${ }^{1}$ \\ ${ }^{1}$ Universidade Estadual de Ponta Grossa, Ponta Grossa, Paraná, Brasil; \\ ${ }^{2}$ Universidade Federal do Paraná, Curitiba, Paraná \\ *Autor correspondente: Isonel Sandino Meneguzzo, Professor Adjunto do Departamento de \\ Geociências - Universidade Estadual de Ponta Grossa. E-mail: meneguzzo@uepg.br. Fone: \\ 42-999121569
}

\section{RESUMO}

O presente estudo teve como objetivo analisar a eficácia de gestão do Parque Nacional dos Campos Gerais, situado no estado do Paraná. Os procedimentos metodológicos envolveram análise de bibliografia referente à área de estudo, legislação pertinente e aplicação de formulário de entrevista. Após estes procedimentos os dados coletados foram confrontados com um método de análise de eficiência de gestão proposto por Faria (2004), baseado nos seguintes âmbitos: Político-legal, Planejamento e Ordenamento, Administrativo, Conhecimento e Qualidade dos Recursos Protegidos. O resultado indicou um porcentual de $48,41 \%$ de eficácia de gestão. Pôde-se constatar que a unidade de conservação possui um índice relativamente baixo de eficiência de gestão, considerando que diversas políticas ambientais ainda não foram implementadas pelo poder público federal.

Palavras-chave: políticas ambientais. conservação da natureza. Campos Gerais do Paraná.

\begin{abstract}
The present study aimed to verify the effectiveness of the management of National Park of the Campos Gerais, located in the state of Paraná. The methodological procedures involved analysis of references pertaining to the study area, relevant legislation and application form for interview. After these procedures the collected data were compared with a method of analysis of management efficiency proposed by Faria (2004), based on the following areas: Law-political, Planning, Management, Knowledge and quality of resources. Analyzing the results collected through the application form to the manager of the unit, came to the percentage of $48.41 \%$ effective management. It could be observed that the protected area has a relatively low level of management efficiency, considering that many environmental policies have not been implemented by the federal government.
\end{abstract}

Key-words: environmental policies. conservation of nature. Campos Gerais of Paraná.

1 O presente artigo é resultado de parte do projeto "Políticas ambientais para a conservação da natureza aplicadas ao Parque Nacional dos Campos Gerais e à Reserva Biológica das Araucárias, Campos Gerais do Paraná". O projeto foi submetido ao COEP/UEPG - parecer número 572.617 e ao ICMBio - autorização número 43.644 . 


\section{INTRODUÇÃO}

O avanço de áreas urbanas e a devastação dos ambientes naturais acarretados pelo aumento de áreas agropastoris na hodierna sociedade capitalista vêm cada vez mais diminuindo as porções vegetais distribuídas no planeta. Áreas que antes eram contínuas estão sendo convertidas em mosaicos fragmentados, ocasionando a redução e o isolamento de populações de espécies nativas, além da perda de habitat, dificultando o fluxo gênico, podendo causar perda de elementos da biodiversidade e até mesmo extinção de espécies (MMA/SBF, 2003).

Para preservar e conservar os recursos naturais algumas estratégias, como o estabelecimento de Unidades de Conservação (UCs), são adotadas para a manutenção da biodiversidade. Estes métodos se baseiam em políticas ambientais que atendem aos princípios de desenvolvimento sustentável e minimização de impactos causados ao meio através do cumprimento da legislação ambiental. Segundo Sousa (2005), as políticas ambientais brasileiras, iniciaram-se de forma tardia em comparação às legislações de outros países, e teve como influência, a pressão realizada por movimentos ambientalistas internacionais. S e g u n d o Meneguzzo e Albuquerque (2009) a política ambiental brasileira adota como instrumento de gestão ambiental o Zoneamento Ecológico-Econômico (ZEE), que parte da proposta de articulação entre os segmentos ambiental e produtivo, porém, sem tocar na mudança da natureza da matriz produtiva.

No Brasil, a sistematização das UCs ocorreu somente no ano de 2000 com a publicação da Lei número 9.985 que cria o Sistema Nacional de Unidades de Conservação (SNUC). Neste, as UCs são classificadas em 12 categorias, divididas em dois grandes grupos: proteção integral, no qual se incluem as categorias Estação Ecológica, Reserva Biológica, Parque Nacional, Monumento Natural e Refúgio de Vida Silvestre; e o grupo de uso sustentável que inclui as categorias Área de Proteção Ambiental, Área de Relevante Interesse Ecológico, Floresta Nacional, Reserva Extrativista, Reserva de Fauna, Reserva de Desenvolvimento Sustentável e Reserva Particular do Patrimônio Natural (BRASIL, 2000). Cada uma delas apresenta objetivos específicos de manejo.

Alguns municípios do Paraná apresentam consideradas áreas de vegeteção pouco alterada sob o aspecto antrópico e, dessa forma, são relevantes para a conservação da biodiversidade no Brasil (MMA/ SBF, 2002). Considerando-se que a floresta com araucária apresentava baixa representatividade no SNUC, o Ministério do Meio Ambiente realizou uma força-tarefa pioneira, em meados da década de 2000, com o objetivo de estudar, identificar, avaliar e propor a criação de UCs que, somadas a outras estratégias de conservação, visavam recuperar e conservar os últimos remanescentes de maior representatividade no sul do Brasil (OLIVEIRA, 2012). Após o levantamento dos dados verificou-se que além de florestas com araucárias, ocorrem também os campos naturais nos Planaltos do Sul do Brasil (OLIVEIRA, 2014). Nesse sentido, o Ministério do Meio Ambiente, criou o Parque Nacional dos Campos Gerais (PNCG) no ano de 2006.

O PNCG, foi criado pelo Decreto Federal sem número de 23 de março de 2006, possui aproximadamente 21.749 hectares, abrangendo áreas dos municípios de Ponta Grossa, Castro e Carambeí (BRASIL, 2006). Sua criação teve como justificativa, a proteção de remanescentes do Bioma Mata Atlântica, composto por Floresta Ombrófila Mista associada à Estepe Gramíneo-Lenhosa (ALMEIDA; MORO, 2007), além de se localizarem estrategicamente nas proximidades de outras duas áreas protegidas, o Parque Estadual de Vila Velha e Área de Proteção Ambiental (APA) da Escarpa Devoniana (OLIVEIRA, 2014).

A categoria Parque Nacional na qual se enquadra o PNCG, conforme o SNUC, possibilita uma maior interação entre o visitante e a biodiversidade, a realização de atividades recreativas, educativas e também permite a realização de pesquisas científicas (BRASIL, 2000).

O Instituto Chico Mendes de Conservação da Biodiversidade (ICMBio), é o órgão ambiental responsável pela sua implementação e gestão, e vem aplicando os procedimentos legais para regularizar a situação fundiária, dentre outros procedimentos.

Constatações empíricas demonstram que medidas efetivas para a regularização desta UC estão sendo realizadas de forma relativamente lenta, o que pode comprometer a conservação dos elementos naturais na área objeto de estudo. Dessa forma, estudos com caráter conservacionista se fazem necessários, no sentido de contribuir para a implementação e gestão desta importante UC federal.

A avaliação da eficácia de gestão de UCs, segundo Andrade (2012), é um instrumento contemporâneo e 
prático, que dentre várias outras contribuições, estimula as organizações a buscarem soluções para os problemas identificados nos métodos de avaliação e, principalmente, vislumbrar a possibilidade de se alcançar um nível mais elevado de qualidade na implementação.

Nesse contexto, a eficácia da gestão do PNCG foi verificada, utilizando uma adaptação da metodologia proposta por Faria (2004) que confronta a situação atual da unidade com as políticas ambientais vigentes.

\section{MATERIAL E MÉTODOS}

\section{ÁREA DE ESTUDO}

A área objeto de estudo (PNCG), situa-se entre os municípios de Ponta Grossa, Castro e Carambeí (Figura 1) (ICMBio, 2014).
No PNCG coexistem originalmente remanescentes de campos e as matas de araucária (MAACK, 2002). Os elementos florestais apresentam-se com frequência, como manchas quase circulares denominadas capões, matas de galeria ou como bosques mistos, especialmente em encostas ou diques de diabásio (MORO, 2001).

As alterações antrópicas de cunho produtivo e a baixa representatividade de áreas protegidas colocam os ecossistemas dos Campos Gerais em situação de vulnerabilidade à perda definitiva de elementos da flora e da fauna e de depredação do patrimônio geológico, geomorfológico representados por afloramentos rochosos, por vezes com presençãs de fósseis e feições de relevo ímpares no contexto brasileiro.

Figura 1: Localização do Parque Nacional dos Campos Gerais em relação ao território paranaense.

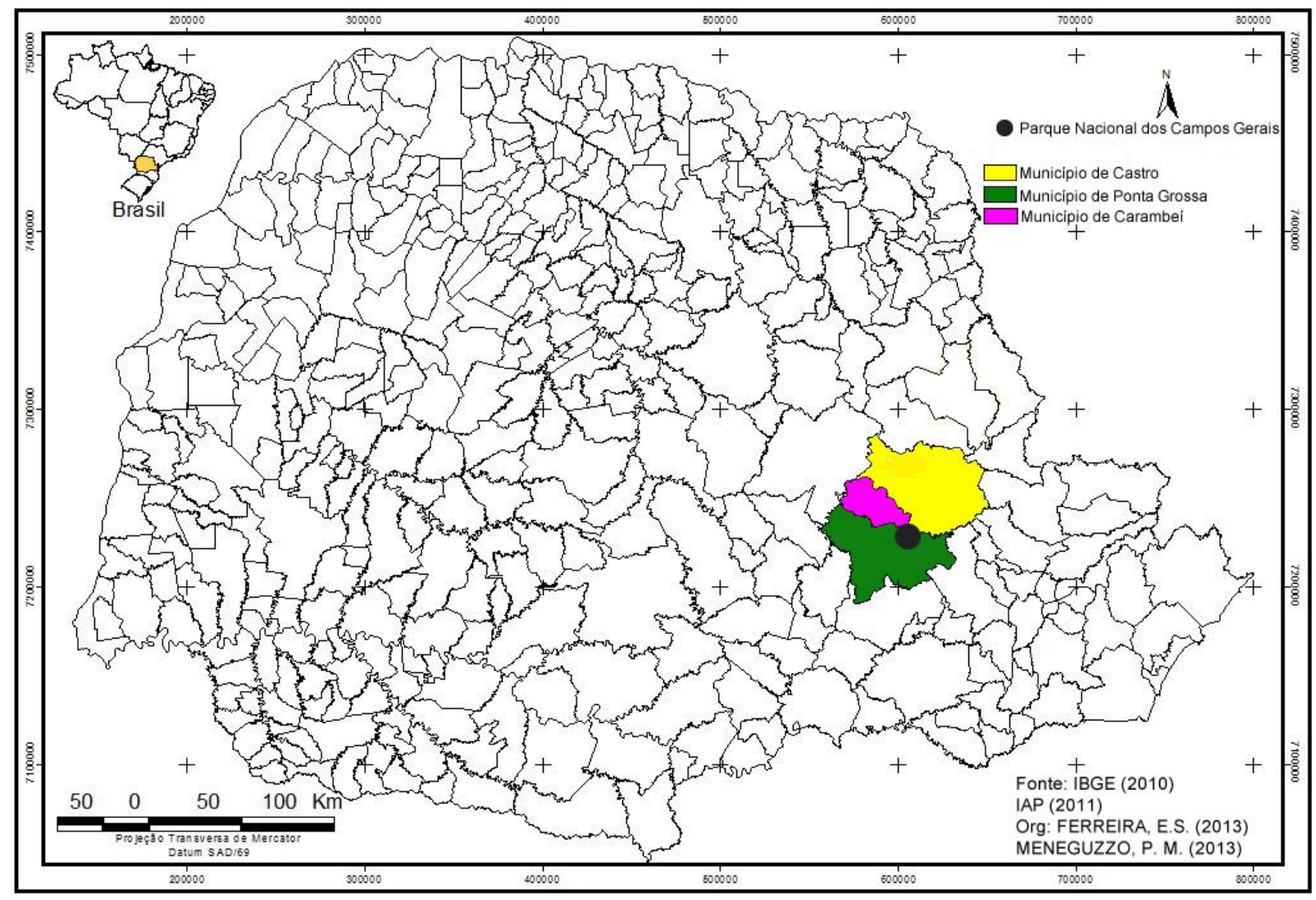

\section{MÉTODOS}

Num primeiro momento, foi realizada a revisão bibliográfica abrangendo o PNCG em seus aspectos gerais, bem como a legislação aplicada à esta categoria de UC. O levantamento de dados envolveu pesquisas em sítios eletrônicos como o do Instituto Ambiental do Paraná (IAP), do (ICMBio) e do Ministério do Meio
Ambiente (MMA). Envolveu também a consulta a artigos e livros que tratam especificamente das UCs inseridas na região dos Campos Gerais do Paraná.

Num segundo momento foi realizada a modificação da metodologia de Faria (2004), para se enquadrar ao contexto da área de estudo.

Foi aplicado um formulário de entrevista ao gestor do PNCG onde 34 questões contemplaram os 
cinco âmbitos para verificação da eficácia de gestão. Os âmbitos são os seguintes: Político-legal, Planejamento e Ordenamento, Administrativo, Conhecimento e Qualidade dos Recursos Protegidos (FARIA, 2004). O formulário de entrevista continha questões que o caracterizam como um questionário estruturado (MARCONI; LAKATOS, 2010) composto de questões fechadas.
A aplicação deste formulário teve como intuito levantar os dados referentes à efetividade da lei do SNUC (BRASIL, 2000), de seu Decreto Regulamentador - Lei número 4.340 de 2002 (BRASIL, 2002) e do Plano Nacional de Áreas Protegidas - Decreto número 5.758 de 2006 (BRASIL, 2006). Os itens avaliados estão listados abaixo (Tabela 1).

Tabela 1 - Âmbitos e critérios abordados no questionário, utilizado na análise da eficácia de gestão do Parque Nacional dos Campos Gerais.

\begin{tabular}{|c|c|}
\hline ÂMBITOS & CRITÉRIOS \\
\hline \multirow{7}{*}{$\begin{array}{l}\text { Planejamento e } \\
\text { Ordenamento }\end{array}$} & Existência e atualidade do plano de manejo \\
\hline & Equipe de planejamento \\
\hline & Zoneamento \\
\hline & Nível de planejamento \\
\hline & Compatibilidade dos usos com os objetivos da unidade \\
\hline & Programa de educação ambiental \\
\hline & Execução do programa de educação ambiental \\
\hline \multirow{8}{*}{ Administrativo } & Formação do administrador \\
\hline & Corpo de funcionários \\
\hline & Recursos e financiamento \\
\hline & Entrega dos recursos \\
\hline & Organização dos arquivos referentes à unidade \\
\hline & Regularização das atividades administrativas \\
\hline & Infraestrutura existente \\
\hline & Equipamentos e materiais da unidade \\
\hline \multirow{9}{*}{ Político-legal } & Instrumento legal de criação \\
\hline & Cumprimento das políticas ambientais vigentes \\
\hline & Estabelecimento do Plano Nacional de Áreas Protegidas \\
\hline & Situação fundiária \\
\hline & Apoio e participação comunitária \\
\hline & Apoio e/ou relacionamento interinstitucional \\
\hline & Plano de carreira dos funcionários \\
\hline & Programa de capacitação \\
\hline & Apoio e/ou facilitação interinstitucional \\
\hline \multirow{6}{*}{ Conhecimento } & Informações biofísicas \\
\hline & Informações cartográficas sobre os recursos naturais \\
\hline & Informações socioeconômicas da unidade e entorno \\
\hline & Disponibilidade e conhecimento das normas jurídicas \\
\hline & Pesquisas e projetos \\
\hline & Acompanhamento de fenômenos naturais, sociais e administrativos \\
\hline \multirow{4}{*}{$\begin{array}{c}\text { Qualidade dos Recursos } \\
\text { Protegidos }\end{array}$} & Tamanho da unidade \\
\hline & Forma aproximada da área e fragmentação da unidade \\
\hline & Isolamento e insularidade \\
\hline & Fatores naturais e antrópicos que afetam a unidade \\
\hline
\end{tabular}


A determinação da eficácia de gestão, segundo Faria (2004), se dá através da análise dos valores encontrados em cada critério, onde os valores integrados resultam em um valor chamado de "total ótimo". No presente estudo, foi estabelecido o mesmo parâmetro apresentado por Faria (2004), onde o valor igual ou superior a $90 \%(\geq 90 \%)$ do total é considerado possuidor de um padrão de excelência de gestão e qualidade da UC.

\section{RESULTADOS}

O âmbito Planejamento e Ordenamento teve como objetivo levantar dados sobre a existência de instrumentos de planejamento, que proporcionem diretrizes mais rígidas, buscando alcançar o cumprimento das funções e das atividades estebelecidas pelo parque. O plano de manejo é um instrumento que se enquadra neste grupo, sendo este o mais importante, pois um planejamento bem organizado e eficiente pode gerar ótimos resultados, e um processo contínuo de formular, revisar e aprovar objetivos propostos. Nesse âmbito, as somas dos máximos que representa o $100 \%$ de eficiência totaliza em 28 pontos, sendo que a somatória dos pontos obtidos se totaliza em apenas 11 pontos, resultando numa efetividade de 39,28\%.

O âmbito Administrativo procurou compreender como se aprensenta o gerenciamento dos recursos protegidos, que dependem diretamente da gestão e aplicação das políticas ambientais estabelecidas para a unidade. Os recursos humanos, infraestrutura, procedimentos administrativos e organizacionais, financiamento e equipamentos em geral são objetos de estudo neste grupo. Na parte administrativa, as somas dos máximos que representa os $100 \%$, toma como total obtido 32 pontos, sendo, portanto, sua efetividade de $56,25 \%$.

Dentro do âmbito Político-Legal, se encontram as políticas ambientais adotadas pela organização, e busca-se averiguar se estão sendo devidademente cumpridas. A legislação é a principal ferramenta que garante que a área se mantenha protegida e que as ações sejam desenvolvidas para a conservação dos recursos. Nesse grupo existem algumas dificuldades em avaliar as políticas através de pontuação, sendo necessário utilizar meios indiretos, avaliando aspectos que expliquem as suas existências e suas aplicações. Nesse âmbito, a eficiência total se dá através da soma que resulta em 36 pontos, embora a somatória obtida para os critérios da unidade se totalize em apenas 19 pontos, resultando numa efetividade de $52,77 \%$.

No âmbito Conhecimento, abordou-se a existência de informações disponíveis por parte dos diretores, que podem ser utilizadas para melhor estruturar e compreender a tamanha complexidade dos recursos pela UC protegidos, além de proporcionar um excelente manejo. Estas são de grande e importante uso para a gestão, como por exemplo, as informações cartográficas, biofísicas, sócioeconômicas e legais. A soma dos máximos neste grupo é 24 pontos e a somatória obtida foram 12 pontos, sendo assim sua efetividade igual $50 \%$.

O quinto e último é o âmbito Qualidade dos Recursos Protegidos. Envolveu a avaliação dos fatores que determinaram a criação da $\mathrm{UC}$, os principais objetivos do manejo da área, o tamanho, a forma, se estas se encontram de maneiras isoladas ou não e também os fatores naturais e antrópicos. A efetividade total corresponde a $43,75 \%$, sendo que o máximo possível é 16 pontos e o somado obtido corresponde a 7 pontos.

Dessa forma, o âmbito que se encontra com uma maior efetividade é o Administrativo com $56,25 \%$ e o que apresenta a menor efetividade é o Planejamento e Ordenamento, sendo que os dois se encontram abaixo do padrão de "excelente eficiência" (Figura 2).

Cabe ressaltar que apesar do valor final da eficácia de gestão do PNCG ter sido baixo, vários critérios receberam notas consideradas altas, remetendo ao fato de que estes são cumpridos de acordo com os objetivos e normas da UC, dentro da realidade possível e do alcance dos gestores, trabalhando com os recursos disponíveis para tal. Outros critérios, porém, obtiveram notas baixas ou medianas por encontrarem-se fora do alcance das pessoas diretamente responsáveis pela gestão do parque.

Dessa forma, fica assim evidente a necessidade de efetivação das políticas públicas ambientais. 
Figura 2 - Resultados obtidos através da aplicação do formulário de entrevista aplicado ao gestor do PNCG.

\section{Eficácia de Gestão do Parque Nacional dos Campos Gerais}

\author{
Padrão de Ótima Eficiência \\ Âmbito Qualidade dos Recursos \\ Protegidos \\ Âmbito Conhecimento \\ Âmbito Político-Lega \\ Âmbito Administrativo \\ Âmbito Planejamento e Ordenamento
}

\section{CONSIDERAÇÕES FINAIS}

Decorridos quase dez anos da criação do PNCG, ainda não foi realizada efetivamente a sua implementação. Nesse sentido, aspectos do seu decreto de criação, do SNUC, do decreto regulamentador do SNUC e do Plano Nacional de Áreas Protegidas não vêm sendo aplicados em sua integridade.

Inúmeras atividades antrópicas impactantes (agricultura, pecuária, mineração, dentre outras) ocorrem no âmbito de propriedades particulares, ainda não desapropriadas (OLIVEIRA, 2014). O uso público, com atividades envolvendo o ecoturismo e esportes de aventura, por exemplo, também constituem-se em atividades consolidadas que ocorrem há décadas na área do PNCG.

Isso acaba comprometendo a realização de outros procedimentos técnico-operacionais, tal como a delimitação em campo da uc, seu zoneamento, a elaboração e a implementação do plano de manejo, o que torna a mesma ainda com usos incompatíveis quando confrontado com seus objetivos de criação. Para que esse uso torne-se o mínimo impactante, se faz necessária a desapropriação da área, para que assim, o poder público federal possa atuar na implementação de políticas públicas ambientais que visem racionalizar o uso do PNCG.

Com a aplicação da metodologia adaptada de Faria (2004) chegou-se ao valor de 48,41\% de eficiência de gestão para o PNCG. Assim, torna-se evidente, a necessidade de se implementarem medidas nos cinco âmbitos (Político-legal, Planejamento e Ordenamento, Administrativo, Conhecimento e Qualidade dos Recursos Protegidos) verificados, para que o parque cumpra efetivamente seus objetivos conforme consta

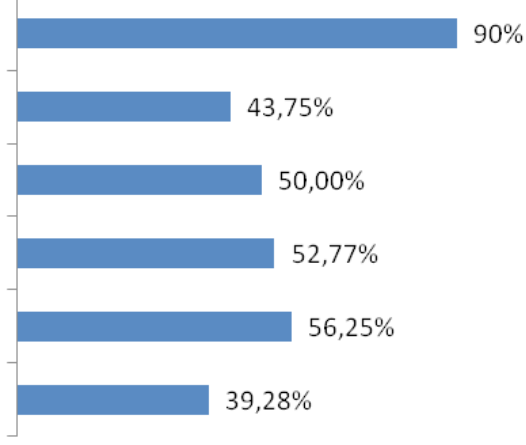

em seu decreto de criação e atenda a Lei número 9.985 de 2000, que instituiu o SNUC.

Portanto, a não implementação das políticas ambientais na área do PNCG, além de comprometer sua eficiência de gestão, também acaba contribuindo para que o patrimônio natural presente no parque esteja vulnerável a impactos ambientais negativos.

\section{REFERÊNCIAS}

ALMEIDA, C. G.; MORO, R. S. Análise da cobertura florestal no Parque Nacional dos Campos Gerais, Paraná, como subsídio ao seu plano de manejo. Ponta Grossa: Terr@ Plural, 2007.v.1, n.1, p.115-122.

ANDRADE, E. A. Avaliação da Eficácia da Política de Gestão de Unidades de Conservação do Estado de Góias. Anápolis, 2012. Trabalho apresentado à defesa no Programa de Mestrado Acadêmico Multidisciplinar em Sociedade, Tecnologia e Meio Ambiente do Centro Universitário de Anápolis - UniEVANGÉLICA.

BRASIL. Lei número 9.985 de 18 de julho de 2000. Disponível em: <http://www.planalto.gov.br/ccivil_03/leis/ 19985.htm> Acesso em: 16/04/2011.

Acesso em: 08 de abril de 2014.

Decreto número 4.340 de 22 de agosto de 2002. Disponível em: < http://www.planalto.gov.br/ccivil_03/ decreto/2002/d4340.htm>. Acesso em 15 de julho de 2014 .

Decreto de 23 de março de 2006. Disponível em: <https://www.planalto.gov.br/ccivil_03/_Ato20042006/2006/Dnn/Dnn10796.htm>. Acesso em 16 de julho de 2014.

Decreto número 5.758 de 13 de abril de 2006. Disponível em: < http://www.planalto.gov.br/ccivil_03/ Ato2004-2006/2006/Decreto/D5758.htm>. Acesso em: $1 \overline{6}$ de julho de 2014. 
FARIA, H. H. Eficácia de Gestão de Unidades de Conservação Gerenciadas pelo Instituto Florestal de São Paulo, Brasil. Presidente Prudente, 2004. Tese apresentada ao Programa de Pós- Graduação em Geografia, setor Desenvolvimento Regional e Planejamento Ambiental Faculdade de Tecnologia da Universidade Estadual Paulista de Presidente Prudente.

ICMBio. Instituto Chico Mendes de Conservação da Biodiversidade. Disponível: <http://www.icmbio.gov.br/ portal/>. Acesso: 08 de Abril de 2014

Instituto Chico Mendes de Conservação da Biodiversidade. Inventário de mamíferos de médio e grande porte na Reserva Biológica das Araucárias e no Parque Nacional dos Campos Gerais. Ministério do Meio Ambiente, 2012.

MAACK, R. Geografia física do estado do Paraná. 3. ed. Curitiba: Imprensa Oficial, 2002.

MARCONI, M. A.; LAKATOS, E. M. Fundamentos de metodologia científica. 7. ed. São Paulo: Atlas, 2010.

MENEGUZZO, I. S.; ALBUQUERQUE, E. S. A política ambiental para a região dos Campos Gerais do Paraná. RA'E GA, n. 18, p. 51-59, 2009.

MMA/SBF - Ministério do Meio Ambiente/Secretaria de Biodiversidade e Florestas. Biodiversidade Brasileira: avaliação e identificação de áreas e ações prioritárias para conservação, utilização sustentável e repartição dos benefícios da biodiversidade nos biomas brasileiros. Brasília, 2002. 52p.

Ministério do Meio Ambiente/Secretaria de Biodiversidade e Florestas. Fragmentação de Ecossistemas: Caudas, efeitos sobre a biodiversidade e recomendações de políticas publicas. Brasília, 2003.

MORO, R. S. A vegetação dos Campos Gerais da Escarpa Devoniana. In: DITZEL, C. H. M.; SAHR, C. L. L. Espaço e cultura: Ponta Grossa e os Campos Gerais. Ponta Grossa: Editora da UEPG, 2001. p. 481-503.

OLIVEIRA, E. A. O Parque Nacional dos Campos Gerais: processo de criação, caracterização ambiental e proposta de priorização de áreas para regularização fundiária. Curitiba, 2012. Tese de Doutorado, Curso de Pós-Graduação em Engenharia Florestal, Setor de Ciências Agrárias, Universidade Federal do Paraná, Curitiba.

Processos de criação de unidades de conservação na floresta com araucárias: o caso do Parque Nacional dos Campos Gerais, ímpar na história da política ambiental brasileira. Curitiba: Editora da UFPR, 2014.

SOUSA, A. C. A. A evolução da política ambiental no Brasil do século XX. Revista de Ciência Política, Rio de Janeiro, n. 30, p. 21-25, 2005.

\section{MATERIAL SUPLEMENTAR}

\section{FORMULÁRIO DE ENTREVISTA}

\section{Âmbito Planejamento e Ordenamento}

1.) Em relação à existência da atualidade de um plano de manejo, assinale a alternativa que melhor se enquadra ao contexto da UC.

( ) Existe um plano de manejo que foi elaborado ou revisado nos últimos anos e que é implementado pela administração da área;

( ) A área está passando por um processo final de elaboração do plano ou trabalha-se em sua revisão;

( ) Há um plano com mais de 5 anos sem revisão, ou estudos básicos visando sua elaboração, ou existe algum outro instrumento de planejamento que orienta as atividades de manejo da unidade;

( ) Há somente um plano de manejo muito desatualizado (>10 anos) que a direção da área já não utiliza;

( ) Não há plano de manejo nem perspectivas de elaboração.

2.) Quais são as características da equipe de planejamento?

( ) Equipe interdisciplinar com participação da comunidade;

( ) Equipe interdisciplinar

( ) Plano elaborado em grupo mais comunidade

( ) Plano elaborado em grupo

( ) Plano elaborado individualmente

3.) Sobre o zoneamento assinale a alternativa que melhor se enquadra ao contexto da UC.

( ) Existe um sistema de zoneamento definido, cujo delineamento incorpora modernos conhecimentos e conceitos técnico-científicos; a regulamentação está estabelecida e os funcionários conhecem devidamente as regras de uso impostas às zonas;

( ) Há as condições acima expostas, porém o zoneamento não é conhecido ou tomado em conta pela totalidade dos funcionários da área;

( ) O zoneamento existente tem algum tempo de implantação, necessitando passar por uma revisão criteriosa devido as mudanças ocorridas (se a área está sendo replanejada, a ponderação pode ser neste nível);

( ) O zoneamento proposto para a área é muito desajustado da realidade e as zonas são pouco reconhecidas e aceitas entre funcionários; suas normas não condizem com os usos e atividades atuais. 
( ) A UC ainda não possui zoneamento.

4.) Em que estágio se encontra o nível de planejamento da UC?

( ) Todos os programas ou atividades desenvolvidas na área tem seus planos específicos sob a orientação de um plano geral; os planos específicos integram-se nos planos operativos anuais;

( ) A área conta com plano de manejo e operativo, porém nem todos os programas ou atividades possuem planos específicos; a área tem amplas perspectivas de melhorar a utilização de instrumentos de planejamento;

( ) Plano de ação emergencial elaborado e com plano de manejo pouco atualizado;

( ) A área possui plano de manejo e operativo junto com alguns documentos que podem ser considerados linhas mestras para algumas atividades;

( ) PAE elaborado para a unidade que nunca teve plano de manejo;

( ) A área possui somente o plano de manejo muito desatualizado, ou este encontra-se em processo de revisão; os técnicos da área necessitam melhorar seus conhecimentos sobre planejamento como instrumento para o manejo inteligente da unidade;

( ) A área carece totalmente de instrumentos de planejamento.

5.) Com relação à compatibilidade dos usos com os objetivos da unidade, assinale a alternativa que melhor se enquadra ao contexto da UC.

( ) Usos compatíveis, de acordo com a capacidade instalada e de suporte da área e sob bom manejo técnico e administrativo;

( ) Usos compatíveis, de acordo com a capacidade instalada e com manejo técnico-administrativo aceitável;

( ) Usos compatíveis, sobre utilizado de acordo com a capacidade instalada e de suporte da unidade e com manejo técnico-administrativo deficiente;

( ) Usos compatíveis, sobre utilizado e sem manejo técnico-administrativo;

( ) Usos incompatíveis e de incidência reduzida sobre os recursos protegidos;

( ) Usos incompatíveis e de incidência mediana sobre recursos, comunidades ameaçadas ou em perigo;

( ) Usos incompatíveis e de elevada incidência, com destruição e perda de recursos.
6.) Quanto a algum programa de educação ambiental na UC, assinale a alternativa que melhor se enquadra ao contexto da UC.

( ) O programa está bem estruturado, abarca todas as ações e atividades para atingir seus objetivos específicos no intuito de alcançar os objetivos da unidade e as atividades desenvolvem-se normalmente;

( ) O programa está estruturado, porém nem todas as atividades planejadas são possíveis de serem realizadas; somente as principais se desenvolvem normalmente;

( ) O programa é parcialmente estruturado, carecendo de insumos específicos para alcançar o nível desejável e necessário frente a seus objetivos;

( ) Algumas atividades inerentes são executadas, mas o programa não existe ou as condições são muito precárias para seu desenvolvimento;

( ) Não existe programa ou atividades relacionadas.

7.) Em relação à execução do programa de educação ambiental, assinale a alternativa que melhor se enquadra ao contexto da UC.

( ) $\geq 90 \%$ das atividades planejadas tem sido executadas;

( ) $76-89 \%$ das atividades planejadas tem sido executadas;

( ) $51-75 \%$ das atividades planejadas tem sido executadas;

( ) 36-50\% das atividades planejadas tem sido executadas;

( ) $\leq 35 \%$ das atividades planejadas tem sido executadas

\section{Âmbito Administrativo}

8.) Qual o nível de formação do administrador da $\mathrm{UC}$ ?

( ) Nível universitário ou mestrado com cursos de especialização, iniciativa alta a média e elevado índice de presença na unidade;

( ) Universitário com cursos de especialização, iniciativa média alta, presença média a alta nos sítios de trabalho;

( ) Universitário, iniciativa média a alta e média presença no local de trabalho;

( ) Nível técnico, iniciativa média a baixa e média a baixa presença local;

( ) Técnico com baixa iniciativa na solução de problemas, presença local baixa; 
( ) Universitário com cursos de especialização, iniciativa média e presença média a alta na unidade;

( ) Técnico com cursos de especialização, iniciativa média a alta na solução de conflitos, índice de presença médio no local de trabalho.

9.) Com relação ao corpo de funcionários, a quantidade atual é:

( ) $\geq 90 \%$ do ótimo;

( ) $76-89 \%$ do ótimo;

( ) $51-75 \%$ do ótimo;

( ) 36-50\% do ótimo;

( ) $\leq 35 \%$ do ótimo.

10.) A respeito dos recursos financiamento da UC, assinale a alternativa que melhor se enquadra.

( ) A área recebe $90 \%$ ou mais do ótimo;

( ) A área recebe entre $76 \%$ e $59 \%$ do ótimo;

( ) A área recebe entre $51 \%$ e $75 \%$ do ótimo;

( ) A área recebe entre $36 \%$ e $50 \%$ do ótimo;

( ) A área recebe $35 \%$ ou menos do ótimo;

11.) Como se dá a regularidade de entrega dos recursos?

( ) A unidade recebe sempre regularmente no período ou datas estabelecidas pela administração central;

( ) Recebe com variações ocasionais;

( ) Há entrega com alguma regularidade, com variações previsíveis;

( ) Há pouca regularidade de entrega, dificultando a execução do planejado;

( ) A entrega de verbas é totalmente irregular.

12.) Como se encontram organizados os arquivos referentes à UC?

( ) Há um sistema de arquivos, complexo e funcional com amplas informações sobre a área e assuntos pertinentes;

( ) Os arquivos são simples mas suficientemente completos para proporcionar um bom suporte à administração;

( ) Os arquivos são incompletos, sem a devida ordem que permita a funcionalidade mínima requerida;

( ) Há os arquivos, porém mal acondicionados, desorganizados e incompletos;

( ) Não há sistema de arquivos de documentos.

13.) Em relação à regularização das atividades administrativas, assinale a alternativa que melhor se enquadra ao contexto da UC.
( ) Há um sistema unificado, moderno e flexível para a normatização dos procedimentos que permite à administração uma perfeita condução e controle das atividades desenvolvidas na área;

( ) O sistema não apresenta integração de todas as atividades, porém é satisfatório em vista da flexibilidade e controle do sistema sobre as principais atividades administrativas;

( ) Existe moderada normatização de atividades, havendo necessidade de integrar e esclarecer a estrutura existente para melhor controle das atividades;

( ) A área apresenta normatização de poucas atividades e todavia não há estrutura requerida para que tais normas cumpram a função de controle;

( ) Não é possível identificar normas de controle administrativo na área.

14.) A infraestrutura existente está adequada à demanda atual e se abarca aos programas e/ou atividades desenvolvidas?

( ) A infra-estrutura está totalmente adequada às necessidades atuais da unidade em quantidade $\mathrm{e}$ qualidade;

( ) As estruturas existentes não são suficientes em quantidade mas possuem qualidade satisfatória que permite atender a maioria das atividades da UC;

( ) Faltam algumas instalações para programas especiais, mas a unidade possui sede administrativa;

( ) Há necessidade de redimensionamento e melhoria das instalações, dada a demanda atual e o estado geral das mesmas. A unidade possui apenas sede administrativa;

( ) As estruturas são insuficientes e de moderada qualidade;

( ) A área carece de instalações essenciais para seu manejo e com sede administrativa parcial;

( ) as estruturas são insuficientes e de baixa qualidade; ( ) Sem nenhuma infra-estrutura; não há um ambiente de trabalho adequado para gerenciar os recursos da área.

15.) A respeito dos equipamentos e materiais da UC, estes se encontram em condições adequadas para uso?

( ) A unidade possui todos os equipamentos e materiais necessários para sua plena operação em perfeitas condições de uso;

( ) Os equipamentos e materiais suprem as demandas, mas as condições de conservação estão medianamente comprometidas; 
( ) Possui transporte e comunicação em boas condições e parte dos demais equipamentos e materiais necessários;

( ) Possui parte dos equipamentos e materiais necessários para o funcionamento da unidade;

( ) Possui equipamento mas não possui material de consumo e/ou vice-versa;

( ) Nenhum equipamento e material para trabalho.

\section{Âmbito Político-Legal}

16.) Em relação ao instrumento legal de criação da $\mathrm{UC}$, qual a alternativa que melhor se enquadra ao contexto atual.

( ) O instrumento jurídico de criação da área é do mais alto nível, encontrando-se atualizado e devidamente regulamentado, em conformidade com as necessidades para o manejo;

( ) O nível do instrumento jurídico de criação da área é satisfatório e encontra-se regulamentado, porém o mesmo necessita adequar-se aos conceitos teóricos sobre o assunto e à realidade política nacional e regional;

( ) O instrumento tem moderado poder em nível de país, ainda que garanta a existência e permanência da área; há necessidade de adequação a conceitos e realidades atuais;

( ) O instrumento jurídico de criação da área é muito inadequado pelo pouco poder que tem, constituindo uma ameaça potencial à permanência da área a longo prazo;

( ) A área não possui nenhum instrumento jurídico de criação.

17.) Sobre o cumprimento das políticas ambientais vigentes (SNUC e seu Decreto Regulamentador) atualmente tem-se:

( ) $\geq 90 \%$ do que as políticas ambientais preconizam é cumprido;

( ) $76 \%$ - $89 \%$ do que as políticas ambientais preconizam é cumprido;

( ) $51 \%$ - $75 \%$ do que as políticas ambientais preconizam é cumprido;

( ) $36 \%$ - 50\% do que as políticas ambientais preconizam é cumprido;

( ) $\leq 35 \%$ do que as políticas ambientais preconizam é cumprido.

18.) No tocante ao que é estabelecido pelo Plano Nacional de Áreas Protegidas atualmente tem-se:
( ) $\geq 90 \%$ do que é preconizado é efetivado;

( ) $76 \%-89 \%$ do que é preconizado é efetivado;

( ) $51 \%-75 \%$ do que é preconizado é efetivado;

( ) $36 \%-50 \%$ do que é preconizado é efetivado;

( ) $\leq 35 \%$ do que é preconizado é efetivado.

19.) Qual a situação fundiária da UC?

( ) $\geq 90 \%$ da área declarada está sob domínio da instituição;

( ) $76 \%$ - 89\% da área declarada está sob domínio da instituição;

( ) $51 \%-75 \%$ da área declarada está sob domínio da instituição;

( ) $36 \%$ - 50\% da área declarada está sob domínio da instituição;

( ) $\leq 35 \%$ da área declarada está sob domínio da instituição.

20.) Como é o apoio e participação comunitária em relação à UC?

( ) Há mecanismos formais de participação comunitária e o apoio dos vizinhos da área é inquestionável; há uma grande geração de benefícios diretos à comunidade;

( ) Não há mecanismos que garantam a participação comunitária, porém ocorre participação informal dos líderes comunitários em sua gestão; devido aos laços criados, há um grau de mediano a alto em termos de geração de benefícios;

( ) Existe ajuda mútua entre a administração e comunidade, porém esta não participa no planejamento e manejo da área, ainda que preste apoio para a sua permanência; a geração de benefícios é média;

( ) Não há cooperação entre a administração e comunidade, porém os vizinhos reconhecem parcialmente o valor intrínseco da área; os benefícios são poucos;

( ) Não há nenhuma forma de cooperação, nem reconhecimento ou apoio comunitário pela área; os benefícios diretos e quantificáveis ou perceptíveis são muito baixos ou não existem.

21.) Como se dá o apoio e/ou o relacionamento interinstitucional do ICMBio?

( ) A) Jurisdição e papel institucional definidos; B) Há coordenação com outros órgãos de atividades conjuntas para a solução de problemas; C) Há intercâmbio de informações, experiências e recursos; D) Não há desenvolvimento de projetos setoriais conflitivos ou incompatíveis com os objetivos da área; 
( ) A definido, e existência de B com maior intensidade que $\mathrm{C}$;

( ) Adefinido, e existência de B com menor intensidade que C;

( ) Somente a circunstância A está definida;

( ) Ocorrem projetos setoriais conflitivos com os objetivos da área e as situações A, B e C não são claras.

22.) Sobre o plano de carreira dos funcionários do ICMBio, assinale a alternativa que melhor se enquadra ao seu contexto.

( ) Os funcionários contam com planos de carreira com progressão gradual que estimula a permanência no serviço e proporciona ânimo para o trabalho;

( ) Há um plano de carreira incipiente e desajustado da realidade. Há incentivos de acordo com as atividades desenvolvidas pelo funcionário;

( ) Não há plano de carreira, porém esforço institucional para sua constituição, com previsão de curto-médio prazo para seu alcance. Ocorrem incentivos esporádicos e seletivos;

( ) Não há um plano de carreira e nenhuma previsão de mudanças. Ocorrem incentivos e apoio ocasionais;

( ) Não há planos de carreira nem incentivos ao pessoal.

23.) Como é o programa de capacitação dos funcionários?

( ) Há um programa de capacitação organizado que é cumprido eficientemente para a especialização dos funcionários;

( ) Há um plano que não é executado em sua totalidade, mas os funcionários recebem satisfatória cota de conhecimento;

( ) Não há um programa oficial regular mas os funcionários recebem certo grau de informações relevantes para o manejo da unidade;

( ) Há um programa documentado e oficial, porém não é ativo ou sofre problemas que impedem o seu desenvolvimento mínimo;

( ) Não existe o programa nem perspectivas de implantação.

24.) Como se dá o apoio e/ou facilitação intrainstitucional?

( ) A instituição tem alta capacidade de apoiar as áreas e a administração local planeja e desenvolve as atividades baseada neste suporte;

( ) Faltam alguns elementos para o excelente apoio, porém há razoável liderança, funcionalidade e comunicação organizacional que proporcionam autonomia administrativa local, assegurando assim um satisfatório apoio;

( ) A estrutura atual da instituição não lhe permite dar assistência estável para as atividades desenvolvidas na unidade;

( ) A instituição necessita evidenciar suas políticas de apoio às áreas: há excesso de entraves burocráticos, pouca autonomia administrativa e uma comunicação ineficiente;

( ) Não há vestígios de apoio institucional à unidade de conservação.

\section{Âmbito conhecimento}

25.) Sobre as informações biofísicas, assinale a alternativa que melhor se enquadra ao seu contexto:

( ) Informações atualizadas e disponíveis na unidade;

( ) Informações atualizadas mas não disponíveis na unidade;

( ) Informações pouco atuais porém disponíveis na área;

( ) Informações pouco atuais e não disponíveis na área; ( ) Informações desatualizadas e disponíveis na unidade;

( ) A área está implementando estudos visando obter as informações necessárias;

( ) Informações desatualizadas e não disponíveis na área;

( ) Inexistência de informações.

26.) Como se encontram as informações cartográficas sobre os recursos naturais protegidos na UC?

( ) Informações atualizadas e disponíveis na unidade;

( ) Informações atualizadas mas não disponíveis na unidade;

( ) Informações pouco atuais porém disponíveis na área;

( ) Informações pouco atuais e não disponíveis na área;

( ) Informações desatualizadas e disponíveis na unidade;

( ) A área está implementando estudos visando obter as informações necessárias;

( ) Informações desatualizadas e não disponíveis na área; 
( ) Inexistência de informações .

27.) Sobre as informações socioeconômicas da UC e de seu entorno, assinale a alternativa que melhor se enquadra ao seu contexto.

( ) Informações atualizadas e disponíveis na unidade;

( ) Informações atualizadas mas não disponíveis na unidade;

( ) Informações pouco atuais porém disponíveis na área;

( ) Informações pouco atuais e não disponíveis na área;

( ) Informações desatualizadas e disponíveis na unidade;

( ) A área está implementando estudos visando obter as informações necessárias;

( ) Informações desatualizadas e não disponíveis na área;

( ) Inexistência de informações.

28.) Emrelaçãoà disponibilidade eao conhecimento externo e interno sobre as principais normas jurídicas incidentes na gestão e manejo da UC, assinale a alternativa que melhor se enquadra ao contexto atual.

( ) Elevada disponibilidade e difusão na unidade, entorno e usuários;

( ) Elevada disponibilidade e moderada difusão;

( ) Moderada disponibilidade e pouca difusão;

( ) Pouca disponibilidade e difusão;

( ) Não há evidencias de informações deste nível na unidade.

29.) Sobre as pesquisas e projetos referentes à UC, assinale a alternativa que melhor se enquadra ao seu contexto.

( ) Os conhecimentos gerados por pesquisas e projetos de desenvolvimento com o patrimônio da área estão disponibilizados na unidade para o aprimoramento do seu manejo e consultas;

( ) Os conhecimentos gerados estão parcialmente disponíveis em cadastros locais e são utilizados para retroalimentar o manejo;

( ) Poucos dos resultados das pesquisas estão disponíveis na unidade e são moderadamente difundidos para a retroalimentação do manejo;

( ) Ainda que não estejam na unidade, os conhecimentos gerados podem ser encontrados na instituição e são pouco difundidos na retroalimentação do manejo;
( ) Os conhecimentos gerados pelos projetos de desenvolvimento e pesquisas não estão disponíveis na unidade e não são conhecidos pelos manejadores.

30.) Em relação à capacidade da UC de implementar sistemas de acompanhamentos de fenômenos naturais, sociais e administrativos que permitam identificar mudanças e tomar decisões adequadas a essas mudanças, assinale a alternativa que melhor se enquadra ao seu contexto.

( ) A área conta com mecanismos eficientes para cobrir adequadamente o monitoramento de fenômenos e atividades desenvolvidas; da mesma maneira conta com meios para retroalimentação de conhecimentos;

( ) A área usa ferramentas de monitoramento para alguns fenômenos naturais e atividades básicas desenvolvidas, usando as informações para a retroalimentação do manejo;

( ) A unidade conta com alguns instrumentos para o monitoramento e retroalimentação, que atendem parcialmente necessidades básicas do manejo;

( ) Há algum mecanismo para o monitoramento e/ ou retroalimentação, mas não são formalizados e sua aplicação não parece ser sistemática;

( ) Não há mecanismos de monitoramento e retroalimentação na área.

\section{Qualidade dos recursos protegidos}

31.) O tamanho da UC é condizente com seus objetivos de criação?

( ) A área possui mais de $90 \%$ da superfície total ótima para salvaguardar os atributos que se deseja conservar;

( ) A área possui entre $76 \%$ e $89 \%$ da superfície total ótima;

( ) A área tem entre $51 \%$ e $75 \%$ da superfície total ótima;

( ) A área tem de 36\% a 50\% da superfície total ótima;

( ) A área possui menos de $35 \%$ da superfície total ótima.

32.) Sobre a forma aproximada da área e a condição de fragmentação da totalidade da área, assinale a alternativa que melhor se enquadra ao contexto da UC.

( ) Forma aproximadamente circular ou muito regular, inteira;

( ) Forma aproximada circular ou oval, regular, fragmentada; 
( ) Forma aproximada crenada, quadrada, moderadamente regular, inteira;

( ) Forma aproximada quadrada ou retangular, fragmentada;

( ) Forma muito irregular, inteira;

( ) Forma muito irregular, fragmentada;

( ) Forma aproximada linear, muito irregular, inteira ou fragmentada.

33.) Em relação ao isolamento ou insularidade, assinale a alternativa que melhor se enquadra ao contexto da UC.

( ) Áreas silvestres contíguas, podendo ser da mesma ou de outras unidades, ou mesmo áreas naturais privadas;

( ) Distância de 2 a $5 \mathrm{~km}$ entre áreas, com corredores e/o u manchas esparsas (stepstones, trampolins ecológicos);

( ) Distância de 2 a $5 \mathrm{~km}$ entre áreas, sem corredores e/ou manchas esparsas;

( ) Distância de 5 a $10 \mathrm{~km}$ entre áreas com corredores e/ou manchas esparsas;

( ) Distância de 5 a $10 \mathrm{~km}$ entre áreas sem corredores e/ou manchas esparsas;

( ) Distância de 10 a 25 km entre áreas com corredores e/ou manchas esparsas;

( ) Distância de 10 a $25 \mathrm{~km}$ entre áreas sem corredores e/ou manchas esparsas;

( ) Distância maior que $25 \mathrm{~km}$ entre áreas.

34.) Sobre os fatores naturais e antrópicos que afetam a estabilidade ambiental, assinale a alternativa que melhor se enquadra ao contexto da UC.

( ) Não há ameaças perceptíveis à unidade;

( ) Fatores causam poucos efeitos ao ambiente protegido;

( ) Fatores cujos efeitos são graves porém são reconhecidos como manejáveis, evitáveis ou de fácil recuperação;

( ) Fatores cujos efeitos são violentos mas podem ser revertidos a médio-longo prazo;

( ) Fatores cujos efeitos são reconhecidos como extremamente violentos e irreversíveis. 